\title{
Adsorption capacity of chosen sandy ground with respect to contaminants relocating with groundwater
}

\author{
Andrzej Aniszewski \\ West Pomeranian University of Technology, Szczecin \\ Civil Engineering and Architecture Faculty
}

*Corresponding author's e-mail: andrzej.aniszewski@zut.edu.pl

\begin{abstract}
Keywords: advection, dispersion, non-linear Freundlich adsorption isotherm, adsorption parameters, groundwater, transport model.
\end{abstract}

\begin{abstract}
One of the most important problems concerning contaminant transport in the ground is the problem related to the definition of parameters characterizing the adsorption capacity of ground for the chosen contaminants relocating with groundwater. In this paper, for chloride and sulfate indicators relocating in sandy ground, the numerical values of retardation factors $\left(R_{q}\right)$ (treated as average values) and pore groundwater velocities with adsorption $\left(u_{x} / R_{a}\right)$ (in micro-pore ground spaces) are taken into consideration. Based on 2D transport equation the maximal dimensionless concentration values $\left(C_{\max }^{*}\right)$ in the chosen ground cross-sections were calculated. All the presented numerical calculations are related to the unpublished measurement series which was marked in this paper as: October 1982. For this measurement series the calculated concentration values are compared to the measured concentration ones $\left(C_{\max m}^{*}\right)$ given recently to the author of this paper. In final part of this paper the parameters characterizing adsorption capacity $\left(R_{a}, u_{x} / R_{a}\right)$ are also compared to the same parameters calculated for the two earlier measurement series. Such comparison also allowed for the estimation of a gradual in time depletion of adsorption capacity for the chosen sandy ground.
\end{abstract}

\section{Introduction}

It can be said that the process of contaminant transport in groundwater in a saturation zone is a complex matter due to the necessity of taking into consideration many overlapping issues, such as:

- types of ground through which contaminants relocate (for example, permeable or more cohesive with different homo-or heterogeneities),

- types of groundwater flow (connected with the above-mentioned types of ground),

- chemism of groundwater in which contaminants relocate (as physico-chemical and biological processes, including for example groundwater temperature, $\mathrm{pH}$ of groundwater or oxidation-reduction potential Eh as so-called redox potential),

- types of agroclimatic zones in relation to various soils (for example, average air temperature, rainfall or the abundance of mineral or organic elements in the soil profile). As for contaminants relocating with groundwater in ground we can deem agroclimatic zones to be combinations of both climatic and ground properties (as overlapping issues - Chiang 2005, Taniguchi and Holman 2010, Zheng and Wang 1996, Szymański and Janowska 2016).

Due to the necessity of rational use and protection of groundwater resources, there has always been the need for improving mathematical models (methods) of defining the transport of contaminants in this water (as convenient ones for appraising groundwater quality). The results achieved through mathematical modeling allow for defining the concentration values in groundwater with relocating contaminants.

Mathematical models for contaminants relocating with groundwater have been used in relation to experimental interpretation, design and prediction in recent decades (Bailey et al. 2013, Chiang 2005, Fang et al. 2012, Mayer et al. 2002, Morway et al. 2013, Yabusaki et al. 2011, Zheng and Wang 1996, Szymański and Janowska 2016). In these transport models, the most important physico-chemical and biological processes have been used, such as: advection, reversible adsorption and biological reactions (biodegradation/denitrification) or radioactive decay. One can also say that mathematical description of all these processes is very complex to model because there is no way to measure the detailed metabolisms inside the ground system (Fang et al. 2012). This remark relates in particular to biological processes (reactions) being considered in soils (Bailey et al. 2013, Fang et al. 2012, Morway et al. 2013, Zheng and Wang 1996).

Simultaneously, we can say that all these mathematical transport models should also be verified in practice, based on in situ concentration measurements of contaminated groundwater. One can say that mutual comparison of earlier calculated concentration values (basing on mathematical models) to the existing in situ measured concentration ones is rather difficult. This fact results, among other things, from: 
- different scale (length) of concentration plumes and simultaneously different and changeable micro and macroscopic ground heterogeneities (as geometrical similarity) (Johnson et al. 2003),

- different numerical data of many parameters being part of these transport models (equations) along with different defining methods of these parameters (Szymański and Janowska 2016),

- inclusion or exclusion of positive or negative sources and sinks in all mathematical models (equations) (see $q_{s}$ parameter in given below equation 1).

Nonetheless, for a general description of all the above-mentioned processes we can use the partial differential governing equation in 3D domain of species $k_{0}$. This equation (as mass balance one with the terms of all the above-mentioned processes) is as follows:

$$
\frac{\partial\left(m C^{k_{0}}\right)}{\partial t}=\frac{\partial}{\partial x_{i}}\left(m D_{i j} \frac{\partial C^{k_{0}}}{\partial x_{j}}\right)-\frac{\partial}{\partial x_{i}}\left(m u_{i} C^{k_{0}}\right)+q_{s} C_{s}^{k_{0}}+\sum R_{n}
$$

where:

$C^{k_{0}}$ the solute concentration in flowing groundwater in aqueous phase (in the local equilibrium conditions) of species $k_{o}\left[g \cdot m^{-3}\right]$,

$u_{i} \quad$ the component of the pore groundwater velocity in pore space $\left[m \cdot s^{-1}\right]$,

$m \quad$ he effective porosity of the porous medium [-],

$x_{i} \quad$ he distance along the Cartesian co-ordinate axis [m],

$D_{i j} \quad$ the hydrodynamic dispersion coefficient symmetrical tensor $\left[m^{2} \cdot s^{-1}\right]$,

$q_{s} \quad$ the volumetric flow rate per unit volume of aquifer representing fluid sources (positive) and sinks (negative) $\left[s^{-1}\right]$,

$C_{s}{ }^{k_{0}}$ the concentration of the source or sink flux for species $k_{o}\left[\mathrm{~g} \cdot \mathrm{m}^{-3}\right]$,

$t \quad$ the co-ordinate of time $[s]$,

$\sum R_{n}$ the function describing generally biological and chemical reactions treated as aqueous-solid surface ones $\left[\mathrm{g} \cdot \mathrm{s}^{-1} \cdot \mathrm{m}^{-3}\right]$ (see the $\sum R_{n}$ function later in the further part of this paper).

The simplified assumptions for all the parameters considered in equation (1) were presented in detail by Aniszewski 2013.

Although the adsorption process in various grounds is relatively known and described in the literature (but still not conclusively), the main problem is related every time to the proper determination of optimum parameters describing this process. However, the adsorption process is understood in this paper as a reversible physical one corresponding to models of statics (in form of various adsorption isotherms) (Chiang 2005, Seidel-Morgenstern 2004).

Adsorption parameters strongly depend on the kind of contaminants relocating with groundwater and agroclimatic zones. It should to be noted that in various agroclimatic zones, physico-chemical and biological processes of relocating contaminated groundwater differ considerably from one another. Based on the literature, we can say that these processes also impact on the adsorption process (Chiang 2005, Fang et al. 2012, Taniguchi and Holman 2010, Zheng and Wang 1996).
One can say that for the temperate agroclimatic zone, accepted in this analysis, we have to deal with negative or positive charging of the solid phase (in the form of "anionic" or "cationic" exchange). However, based on the literature, we can also say that sandy ground is probably negatively charged (Chiang 2005, Seidel-Morgenstern 2004, Taniguchi and Holman 2010, Zheng and Wang 1996).

Simultaneously, when the molecular diffusion in sandy ground is negligible (just like in the ground accepted for this analysis), we can always make reference to faster movement of chlorides compared to groundwater flow (in contrast to sulfate indicators). This is caused mainly by exclusion of "anionic" exchange with higher "cationic" exchange at the same time (Chiang 2005, Seidel-Morgenstern 2004, Taniguchi and Holman 2010). Thus, this faster movement of chlorides also leads to a considerably lower adsorption value (adsorption capacity) for chloride indicators compared to sulfate ones, respectively.

On the other hand, we can also recognise the gradual depletion in time of the adsorption capacity in ground in relation to the adsorption process, as a process that causes the greatest concentration reduction values. However, adsorption capacity is understood in this paper as adsorption value corresponding to ground micro-pore volume filling (Chiang 2005, Seidel-Morgenstern 2004). These above-mentioned remarks can also be confirmed by the following chosen parameters characterizing adsorption capacity given below:

- decreasing gradually in time the calculated values of retardation factors $\left(R_{a}\right)$ (treated in this paper as average values),

- increasing gradually in time real pore groundwater velocities $\left(u_{x} / R_{a}\right)$ (in micro-pore spaces) as a result of the adsorption process.

Thus, all of the above-mentioned remarks are vitally important in the context of:

- chosen chloride and sulfate indicators relocating with groundwater in the accepted sandy ground (accepted as homogeneous and fine sand - see Aniszewski 2009),

- lower (for chlorides) and higher (for sulfates) adsorption capacity (as adsorption value), resulting from all the calculations made in this paper (as confirmation of all the above-mentioned remarks - see also the $R_{a}$ and $u_{x} / R_{a}$ parameters, Table 1 and Figs. 1 and 2).

We can also say that the so called retardation factors $\left(R_{a}\right)$ depend on contaminant concentration values in ground systems and simultaneously do not depend on ground porosity (Chiang 2005). One can say that all the calculated retardation factors $\left(R_{a}\right)$ will gradually approach the values $R_{a} \cong 1.00$ (for the total depletion of adsorption capacity of porous media). Simultaneously, this means that the $S$ value, as the mass of the solute species adsorbed on the grounds per unit bulk dry mass of the porous medium, will gradually approach the zero value $S \cong 0$ (see equation 1$)$.

As mentioned in the abstract, the calculations of both the $\left(R_{a}, u_{x} / R_{a}\right)$ parameters and the $\left(C_{\text {max }}^{*}\right)$ concentrations for chlorides and sulfates are the main topics of this paper. All of the calculations presented here concern the unpublished measurement series of October 1982. Additionally, the parameters calculated here $\left(R_{a}, u_{x} / R_{a}\right)$ are also compared to the same parameters in relation to the two earlier measurement series for the same studied sandy ground presented by 
Aniszewski 2009 (November 1981) and Aniszewski 2013 (May 1982).

\section{Material and methods}

Taking into consideration in equation (1) advection, two-dimensional dispersion, adsorption process $(R \neq 1)$ and neglecting simultaneously biological and chemical reactions in the ground ( $\sum R_{n}=0$ ), the simplified $2 \mathrm{D}$ form of equation (1) can be expressed as follows:

$$
\frac{\partial C}{\partial t}\left(1+\frac{\rho}{m} \frac{\partial S}{\partial C}\right)+u_{x} \frac{\partial C}{\partial x}=D_{x} \frac{\partial^{2} C}{\partial x^{2}}+D_{y} \frac{\partial^{2} C}{\partial y^{2}}
$$

where:

$S \quad$ the mass of the solute species adsorbed on the grounds per unit bulk dry mass of the porous medium (in the local equilibrium conditions) $[-]$,

$D_{x}, D_{y} \quad$ the components of the longitudinal and transverse dispersion coefficients along the $\mathrm{x}$ and $\mathrm{y}$ axes that depend on the longitudinal and transverse dispersivities $\left(\alpha_{L}, \alpha_{T}\right)\left[\mathrm{m}^{2} \cdot \mathrm{s}^{-1}\right]$,

$[1+(\rho / m) \cdot(\delta S / C)]$ the constant in time, so-called retardation factor $R(R \neq 1.00)$ resulting from adsorption process [-] (Chiang 2005).

The explanation of all the remaining parameters being considered in equation (2) is given earlier under equation (1). The adopted assumptions were related to in situ measurements made by the Institute of Environmental Development in Poznań (cited by Aniszewski 2009).

The source of groundwater contamination in the chosen site (aquifer) was a real ground lagoon (marked by its user as lagoon 4). The lagoon 4 was filled with liquid manure from a pig breeding farm, "Redło", near Świdwin and located in the West Pomeranian Voivodeship of Poland. For the exact examination of contaminants relocating with groundwater, a certain number of piezometers were installed near the existing ground lagoon 4.

An illustrative map of only the chosen natural site, along with a detailed numeration of the existing and chosen four piezometers is presented by Aniszewski 2013. These four piezometers were used in numerical calculations based on the dimensionless transport model presented below (3) (see also in Table 1 all of these piezometers with both their numeration and distances from the leakage source lagoon 4).

Such late, in a sense of time, measurement series of October 1982 adopted for analysis and calculations was taken in this paper intentionally due to access for a short time to the measurement series of October 1982 presented here with the necessary field data (as the last part of the technical report cited by Aniszewski 2009 - see also final acknowledgements).

The dimensionless form of equation (2) is the following:

$$
\frac{\partial C^{*}}{\partial \tau}+A_{1}^{*} \frac{\partial C^{*}}{\partial \xi}=A_{1}^{*} \cdot D_{x}^{*} \frac{\partial^{2} C^{*}}{\partial \xi^{2}}+A_{1}^{*} \cdot D_{y}^{*} \frac{\partial^{2} C^{*}}{\partial \eta^{2}}
$$

in which the following auxiliary dimensionless parameters were taken into account:

$$
\begin{aligned}
& \frac{x}{L}=\xi ; \quad \frac{y}{L}=\eta ; \quad \frac{C}{C_{o}}=C^{*} ; \quad \frac{u_{x} t}{L}=\tau ; \quad \frac{D_{x}}{u_{x} L}=D_{x}^{*} \\
& \frac{D_{y}}{u_{x} L}=D_{y}^{*} ; \quad \frac{m}{m+\rho N K C_{o}^{(N-1)} C^{*(N-1)}}=A_{1}^{*}
\end{aligned}
$$

The $L$ parameter presented in equation (4) represents the measured distance from the source of the contaminant outflow (as lagoon 4) to the last cross-section [as piezometer $\mathrm{X}(5)]$ in the chosen ground and the $C_{o}$ parameter represents the initial measured contaminant concentrations in the source of the outflow into the chosen natural aquifer. The initial numerical $C_{o}$ concentration values (for the chosen chloride and sulfate indicators) are given in a further part of this paper for the measurement series analysed here of October 1982.

For the numerical solution of equation (3), appropriate initial and boundary dimensionless conditions (presented by Aniszewski 2009) were also adopted. The updated computational program "PCCS -2.1 " was used by the author for numerical calculations of the dimensionless maximum concentrations $\left(C_{\max }^{*}\right)$ (see Table 1$)$.

For a description of the adsorption term in equation (3), the Freundlich non-linear isotherm $\left(S=K \cdot C^{N}\right)$ was assumed, as the isotherm is often used in practice due to its simple mathematical notation (Chiang 2005, Seidel-Morgenstern 2004).

The numerical values of the $K$ and $N$ parameters were calculated based on the author's updated laboratory research for all the chosen indicators just in relation to the measurement series of October 1982 analysed here. The updated numerical values of the $K$ and $N$ parameters are: $K=0.3098 \mathrm{~m}^{3} \cdot \mathrm{g}^{-1}$ and $N=0.4978$ for the chloride indicator and $K=1.0645 \mathrm{~m}^{3} \cdot \mathrm{g}^{-1}$ and $N=0.7269$ for the sulfate indicator, respectively. All these above numerical values of the $K$ and $N$ parameters differ (as smaller ones) from the $K$ and $N$ parameters related to the two earlier measurement series presented by Aniszewski 2009 and Aniszewski 2013.

So, using the parameters $K$ and $N$, the general equation describing the dimensionless retardation factor $(R)$ in equation (2) takes the form:

$$
R=1+\frac{\rho}{m} \cdot \frac{\partial S}{\partial C}=1+\frac{\rho}{m} \cdot N \cdot K \cdot C^{(N-1)}
$$

Numerical values of the calculated retardation factors $(R)$ based on equation (5) (treated as average values $R_{a}$ ) for the two chosen indicators are given in the explanations under Table 1 (in footnotes 1 and 2). According to the measurement series of October 1982 presented here, the initial measured contaminant concentrations in the source of the outflow into the chosen natural aquifer (being lagoon 4 with liquid manure inside) are: $C_{o} \approx 309.0 \mathrm{~g} \cdot \mathrm{m}^{-3}$ for chlorides and $C_{o} \approx 405.0 \mathrm{~g} \cdot \mathrm{m}^{-3}$ for sulfates, respectively.

These above-mentioned initial numerical $C_{o}$ concentration values for the measurement series analysed here differ also (as greater ones) from the $C_{o}$ ones related to the two earlier measurement series.

The dimensionless initial measured contaminant concentrations in relation to the initial measured contaminant 
ones in lagoon 4, for the two indicators presented here, are also given in Table 1 as footnote a (as values equal to 1.00).

All the measured concentration data $\left(C_{o}\right.$ and $\left.C^{*}{ }_{\max m}\right)$ related to both the measurement series of October 1982 analysed here and the chosen indicators were described in the last part of the technical report. This report, cited by Aniszewski 2009, was recently given to the author (see also final acknowledgements).

It should be noted that the measured chloride and sulfate concentration values $\left(C_{\max m}^{*}\right)$ between the particular piezometers are burdened with certain measurement errors. For this reason the variation between them does not have the character of an exponential curve.

Thus, these measured concentrations (for chlorides and sulfates) were not combined between the particular piezometers in Figs. 3 and 4. At the same time, the numerical optimum values of all the remaining required parameters being considered in the presented equation (3) (as updated parameterization of this equation in relation to both the two chosen contaminants and the considered sandy ground medium) are the following:

$-\left(u_{x}=1.17 \times 10^{-3} \mathrm{~m} / \mathrm{s}, \rho=1.69 \mathrm{~g} / \mathrm{m}^{3}, \quad m=0.38\right)$ as the adopted real ground parameters in relation to the measurement series of October 1982 (based on last part of the technical report cited by Aniszewski 2009),

$-\left[D_{x}=7.21 \times 10^{-3} \mathrm{~m}^{2} / \mathrm{s}\left(\alpha_{L}=7.0 \mathrm{~m}\right), D_{y}=6.08 \times 10^{-4} \mathrm{~m}^{2} / \mathrm{s}\right.$ $\left.\left(\alpha_{T}=0.56 \mathrm{~m}\right)\right]$ as the optimum dispersion parameters calculated by the author of this paper.

The above-mentioned parameter values related to the measurement series of October 1982 differ from the ones related to the two earlier measurement series. One can say, for example, that in all cases the dispersion parameter values $\left(D_{x}, D_{y}\right)$ are smaller than those calculated in the two earlier measurement series (presented by Aniszewski 2009 and Aniszewski 2013).

\section{General description of applied numerical solution}

In the numerical calculations the computational program "PCCS - 2.1" mentioned earlier was chosen, also using the well-known "upwind" scheme (being an "explicit" finite difference one that is described, in detail, e.g, by Szymkiewicz 2010). This program allows one to obtain the dimensionless values of the contaminant concentrations in the range $<0,1>$. In the adopted numerical solution of equation (3), the values of dimensionless steps of the difference scheme grids $\left[h^{*}(\Delta x)\right.$, $k^{*}(\Delta y)$ and $\left.w^{*}(\Delta t)\right]$ were taken based on Aniszewski 2013 and under the certain assumptions:

$$
P e=\frac{u_{x} \cdot \Delta x(\Delta y)}{D_{x}\left(D_{y}\right)}=\frac{u_{x} \cdot \Delta x(\Delta y)}{\alpha_{L} \cdot u_{x}\left(\alpha_{T} \cdot u_{x}\right)}=\frac{\Delta x(\Delta y)}{\alpha_{L}\left(\alpha_{T}\right)} \leq 2
$$

and

$$
C_{a}=u_{x} \cdot \Delta t / \Delta x \leq 1
$$

Such numerical values of both the Peclet $\left(P_{e}\right)$ and the Courant $\left(C_{\alpha}\right)$ numbers minimize simultaneously the "numerical dispersion" and "artificial oscillations" in relation to equation (3), where the contaminant transport in ground is dominated not only by the advection process.

For such above-mentioned assumptions, the well-known "upwind" scheme (being an "explicit" finite difference one) is particularly suitable for numerical calculations (Szymkiewicz 2010). In these numerical calculations the important consistency, stability and convergence conditions were also preserved. The Peclet number constraint is often relaxed outside the area of interest, where a lower predictive accuracy is acceptable.

More details concerning both the applied numerical solution and method of numerical calculations used by the author are given by Szymkiewicz 2010, Aniszewski 2009 and Aniszewski 2013.

\section{Results of research}

All the results of the numerical calculations, presented here, of the dimensionless concentration values $\left(C_{\max c}^{*}\right)$ according to equation (3) along with the dimensionless measured concentration values $\left(C_{\max m}^{*}\right)$ in the chosen four piezometers are given in Table 1.

Table 1. Calculated $\left(C_{\max }^{*}\right)$ and measured $\left(C_{\max m}^{*}\right)$ values of the contaminant concentrations in the measurement series

\begin{tabular}{|c|c|c|c|c|c|}
\hline \multirow{2}{*}{ 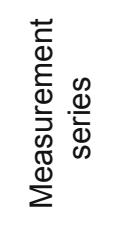 } & \multirow{2}{*}{$\begin{array}{l}\text { Chosen contamination } \\
\text { in relation to } \\
\text { considered processes }\end{array}$} & \multicolumn{4}{|c|}{$\begin{array}{l}\text { Numbers of chosen piezometers with dimensionless }(\xi) \text { and dimensional }(x) \text { distances from } \\
\text { the leakage source in lagoon } 4 \text { [total distance } L \text { to the last piezometer } X(5)-L \approx 105.0 \mathrm{~m} \text { ] }\end{array}$} \\
\hline & & $\begin{array}{c}\text { III (8) } \\
\xi \approx 0.38 \\
x \approx 40.0 \mathrm{~m}\end{array}$ & $\begin{array}{c}\mathrm{IX}(4) \\
\xi \approx 0.66 \\
\mathrm{X} \approx 70.0 \mathrm{~m}\end{array}$ & $\begin{array}{c}\text { VII }(6) \\
\xi \approx 0.86 \\
x \approx 90.0 \mathrm{~m}\end{array}$ & $\begin{array}{c}X(5) \\
\xi \approx 1.00 \\
X(L) \approx 105 \mathrm{~m}\end{array}$ \\
\hline \multirow{2}{*}{ 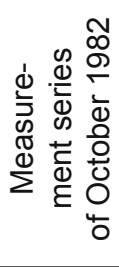 } & $\begin{array}{l}\text { Chlorides }(\mathrm{NaCl}) \\
\text { [adsorption } \\
\text { process] }\end{array}$ & $\begin{array}{c}0.4176^{1)} \\
1.00^{\mathrm{a})} \\
\left(C_{\max m}^{*}=0.3906\right)\end{array}$ & $\begin{array}{c}0.2399^{1)} \\
1.00^{\mathrm{a})} \\
\left(C_{\max m}^{*}=0.2274\right)\end{array}$ & $\begin{array}{c}0.1628^{1)} \\
1.00^{\mathrm{a})} \\
\left(C_{\max m}^{*}=0.1588\right)\end{array}$ & $\begin{array}{c}0.1172^{1)} \\
1.00^{\mathrm{a})} \\
\left(C_{\max m}^{*}=0.1065\right)\end{array}$ \\
\hline & $\begin{array}{l}\text { Sulfates }\left(\mathrm{Na}_{2} \mathrm{SO}_{4}\right) \\
\text { [adsorption } \\
\text { process] }\end{array}$ & $\begin{array}{c}0.3256^{2)} \\
1.00^{\mathrm{a})} \\
\left(C_{\max m}^{*}=0.3048\right)\end{array}$ & $\begin{array}{c}0.1562^{2)} \\
1.00^{\mathrm{a})} \\
\left(C_{\max m}^{*}=0.1489\right)\end{array}$ & $\begin{array}{c}0.0982^{2)} \\
1.00^{\mathrm{a})} \\
\left(C_{\max m}^{*}=0.0969\right)\end{array}$ & $\begin{array}{c}0.0782^{2)} \\
1.00^{\mathrm{a})} \\
\left(C_{\max m}^{*}=0.0690\right)\end{array}$ \\
\hline
\end{tabular}
of October 1982

Explanations: ${ }^{1)} \mathrm{MDC}$ (maximal dimensionless concentrations $C_{\text {max }}^{*}$ ) according to equation (3) with adsorption $\left(R_{\mathrm{a}}=1.01\right.$ for chlorides), ${ }^{2)} \mathrm{MDC}$ according to equation (3) with adsorption $\left(R_{\mathrm{a}}=2.04\right.$ for sulfates), a) Initial dimensionless concentrations in relation to the initial measured ones in the lagoon 4 with liquid manure (for the presented here unpublished measurement series of October 1982). 


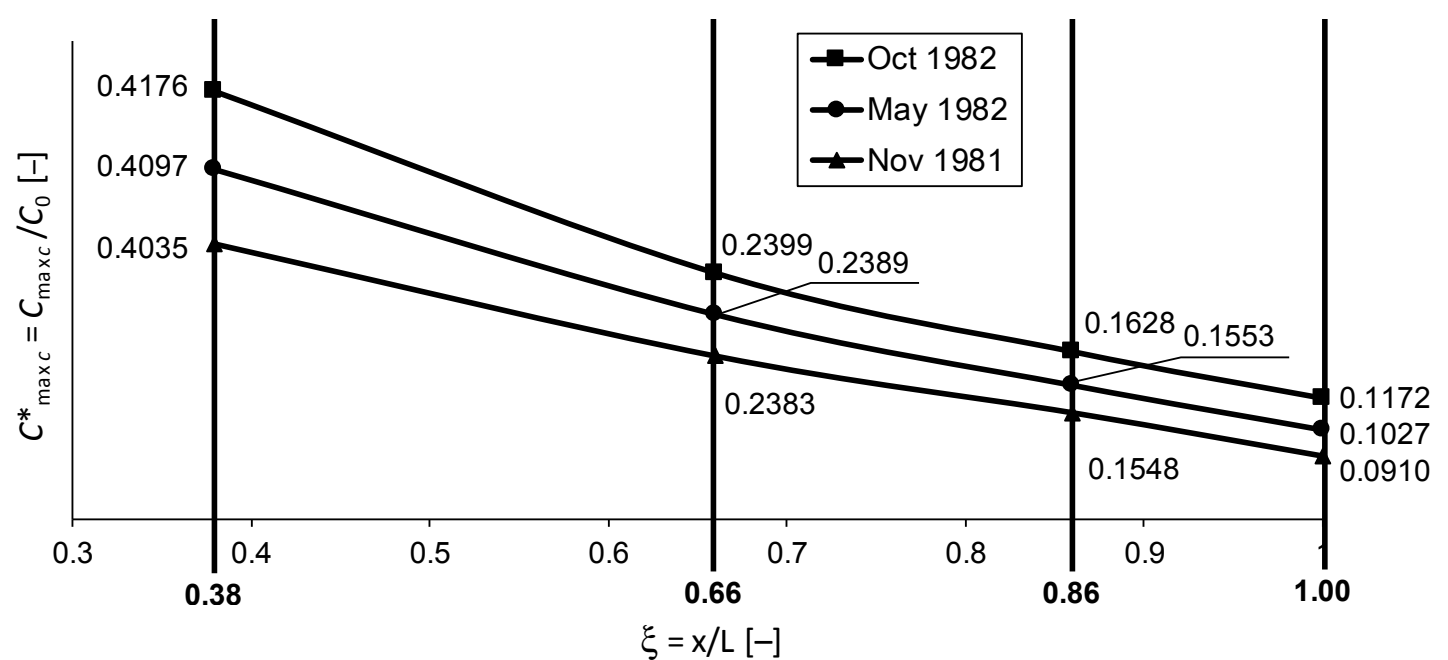

Fig. 1. Dimensionless values of the calculated chloride concentrations $\left(C_{\text {max }}^{*}\right)$ (based on equation 3) both for the measurement series analysed here (Oct 1982) and the two earlier ones

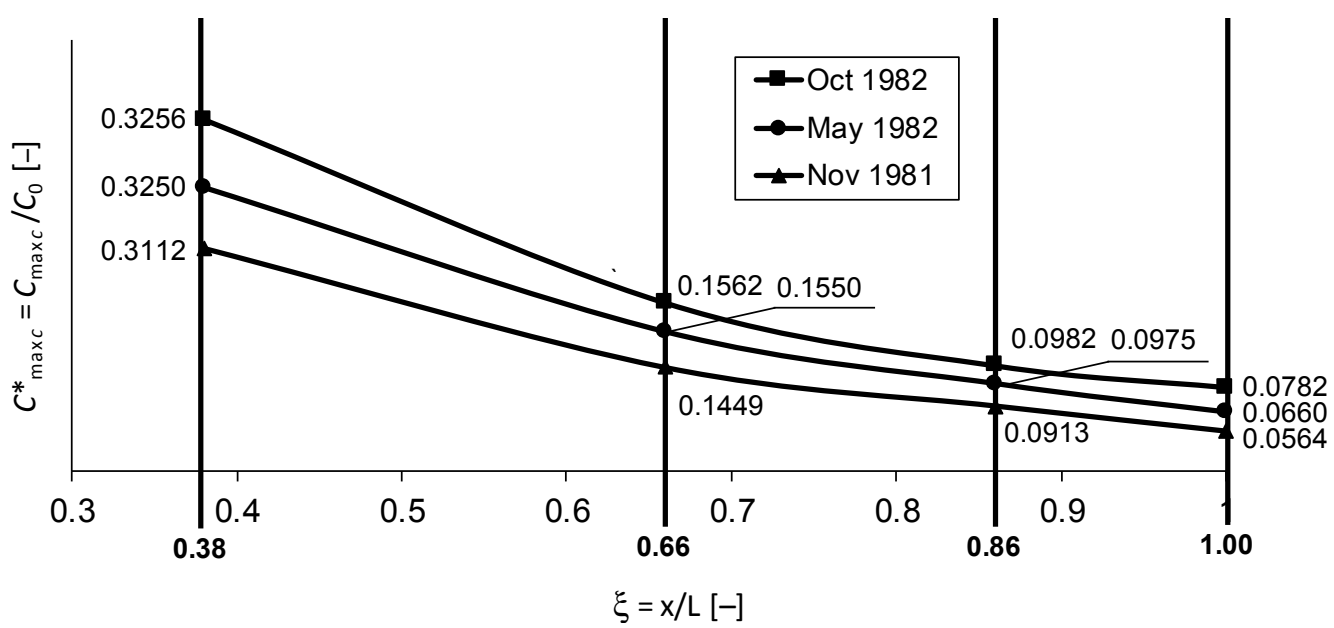

Fig. 2. Dimensionless values of the calculated sulfate concentrations $\left(C_{\max c}^{*}\right)$ (based on equation 3$)$ both for the measurement series analysed here (Oct 1982) and the two earlier ones

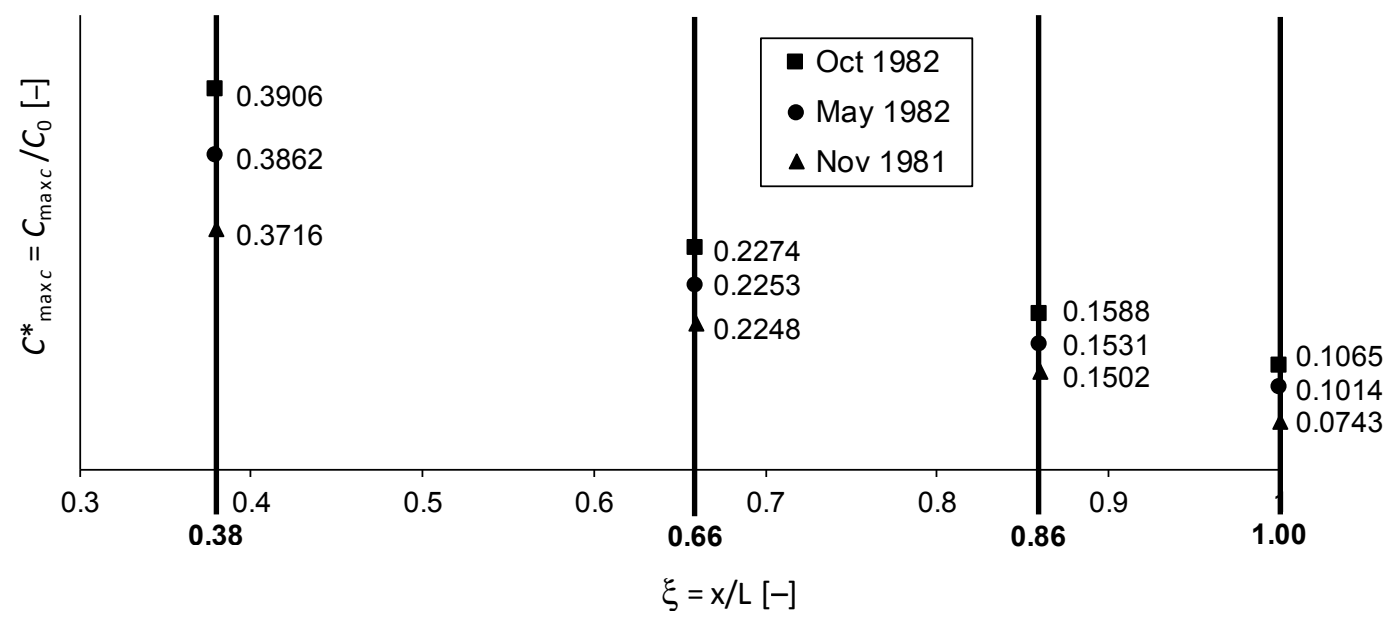

Fig. 3. Dimensionless values of the measured chloride concentrations $\left(C_{\max m}^{*}\right)$ both for the measurement series analysed here (Oct 1982) and the two earlier ones 


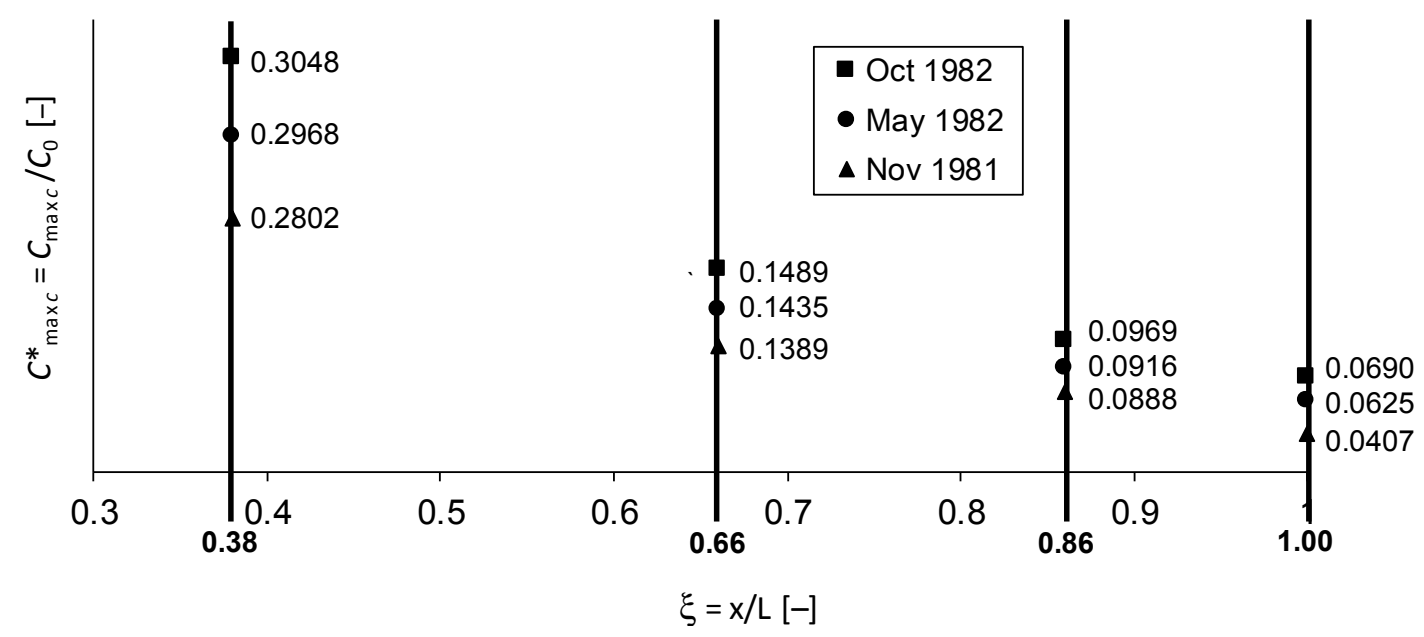

Fig. 4. Dimensionless values of the measured sulfate concentrations $\left(C_{\max m}^{*}\right)$ both for the measurement series analysed here (Oct 1982) and the two earlier ones

Based on the numerical calculations given in Table 1 , it was possible to calculate the $\left(R, u_{x} / R_{a}\right)$ parameters for the measurement series of October 1982:

- the dimensionless value of $\left(R_{a}\right)$ amounts to 1.01 for chlorides - see explanations under Table 1 (footnote 1) and 2.04 for sulfates - see explanations under Table 1 (footnote 2). However, the greater values of these parameters calculated for sulfates of the two earlier measurement series amount to: $R_{a}=2.18$ (November 1981 ) and $R_{a}=2.11$ (May 1982),

- the dimensional value of $\left(u_{x} / R_{a}\right)$ amounts to $1.16 \cdot 10^{-3}$ $\left[\mathrm{m} \cdot \mathrm{s}^{-1}\right]$ for chlorides and $0.57 \cdot 10^{-3}\left[\mathrm{~m} \cdot \mathrm{s}^{-1}\right]$ for sulfates in relation to the initial real pore velocity of groundwater $u_{x}=1.17 \cdot 10^{-3}\left[\mathrm{~m} \cdot \mathrm{s}^{-1}\right]$ (without adsorption process $R_{a}=1.00$ ). However, the lower values of these parameters calculated also for sulfates of the two earlier measurement series amount to: $u_{x} / R_{a}=0.53 \cdot 10^{-3}\left[\mathrm{~m} \cdot \mathrm{s}^{-1}\right]$ (November 1981) and $u_{x} / R_{a}=55 \cdot 10^{-3}\left[\mathrm{~m} \cdot \mathrm{s}^{-1}\right]$ (May 1982).

Graphic results of the numerical values of the calculated concentrations are given in Figs. 1 and 2 (as black square symbols). However, the measured concentration values are given respectively in Figs. 3 and 4 (also as black square symbols).

Simultaneously, both the calculated and the measured concentrations for the two earlier measurement series are also given in Figs. 1, 2, 3 and 4 (as black circle and triangle symbols, respectively).

\section{General conclusions}

1. Taking into consideration the calculated value of the average dimensionless retardation factor $\left(R_{a}=1.01\right)$, in relation to chlorides, we can point out the almost total depletion of adsorbing capacity for the last measurement series of October $1982\left(R_{a}=1.01 \cong 1.00\right.$ and $\left.S=0\right)$. In relation to sulfates, we can indicate a considerably lower depletion of adsorbing capacity because the time for total depletion of the adsorbing capacity in this case will be considerably longer $\left(R_{a}=2.04>1.00\right.$ and $\left.S \neq 0\right)$.

2. Nonetheless, taking also into consideration the numerical values of $\left(R_{a}, u_{x} / R_{a}\right)$ parameters for the two earlier series of November 1981 (Aniszewski 2009) and May 1982 (Aniszewski 2013), one can finally mention a gradual depletion in time of the adsorbing capacity for the analysed ground. This above-mentioned remark can only be related to a more or less one year period of time (as the series: November1981 - May 1982 - October 1982), chosen indicators (i.e., chlorides and sulfates) as well as the fine sandy ground.

3. It should also be emphasized that all the measured concentration values for all the contaminants chosen here are lower compared to the calculated ones (see Table 1). This creates a greater margin of error for the prognosis and simulation of concentration values calculated based on the presented transport model (3). In the opposite case, the practical use of the presented transport model (3) could be questionable for calculations of contaminant concentrations in the chosen ground.

4. The calculations presented in this paper also prove that the chosen contaminants (i.e., chlorides and sulfates) distinguish different adsorbing capacity (as adsorption value) during their relocating with groundwater in the chosen sandy ground. For sulfates, this capacity is considerably higher compared to chlorides, which have a considerably lower one (see Table 1 and Figs. 1 and 2). This regularity also occurs for the two earlier measurement series of November 1981 (Aniszewski 2009) and May 1982 (Aniszewski 2013).

5. Based on Figs. 3 and 4, it should also be noticed that all the measured concentration values from the measurement series of October 1982, presented here, are the greatest ones compared to the measured concentration values in the two earlier measurement series presented by Aniszewski 2009 and Aniszewski 2013. One can say that this regularity is caused mainly by the adsorbing capacity decreasing in time (as adsorption value) for the same sandy natural ground.

6. Nonetheless, it should also be to note that all the above-mentioned general conclusions can only be related to the contaminants analysed here relocating with groundwater in the chosen fine sandy ground. Transmission of all these conclusions (based on the calculations made in this paper) to other contaminants and grounds (other agroclimatic zones) would be highly questionable. 


\section{Acknowledgements}

The author wishes to acknowledge the Management of the Agricultural Complex Smardzko-farm (a swine farm) in Redło near Świdwin (in the West Pomeranian Voivodeship of Poland) for making accessible the unpublished technical report (in Polish) with measured maximal concentration values and ground parameters (which forms last part of this report). All of these data were related to the measurement series of October 1982 analysed in this paper. This report was used by the author in numerical calculations (for all chosen contaminants and piezometers). This unpublished report is cited by Aniszewski 2009 and may be obtained from the author (this information is also given in the earlier part of this paper).

\section{References}

Aniszewski, A. (2009). Mathematical modeling and practical verification of groundwater and contaminant transport in a chosen natural aquifer, Acta Geophysica, 57, pp. 435-453, DOI: $10.2478 / \mathrm{s} 11600-008-4$.

Aniszewski, A. (2013). Description and verification of the contaminat transport models in groundwater (theory and practice), Archives of Environmental Protection, 39, pp. 3-21, DOI: 10.2478/aep2013-0021.

Bailey, R.W., Morway, E.D., Niswonger, R.CH., \& Timothy, T.K. (2013). Modeling variably saturated multispecies reactive ground water solute transport with MODFLOW-UZF and T3D, Ground Water, 51, pp. 752-761, DOI: 10.1111/j.17456584.2012.01009.x.

Chiang, W.-H. (2005). 3D-Groundwater Modeling with PMWIN: A Simulation System for Modeling Groundwater Flow and Trans port Processes, Springer, Verlag, Berlin-Heidelberg-New York 2005.

Fang, Y., Wilkins, M.J., Yabusaki, S.B., Lipton, M.S. \& Long, P.H.E. (2012). Evaluation of a genome-scale in silico metabolic model for Geobacter metallireducens by using proteomic data from a field biostimulation experiment, Applied and Environmental Microbiology, 78, pp. 8735-8742, DOI:10.1128/AEM.01795-12.
Johnson, G.R., Gupta, K., Putz, D.K., Hu, Q., \& Brusseau, M.L. (2003). The effects local-scale physical heterogeneity and nonlinear rate-limited sorption-desorption on contaminant transport in porous media, Journal of Contaminant Hydrology, 64, pp. 35-58, DOI: 10.1016/S0169-7722(02)00103-1.

Mayer, K.U., Frind, E.O., \& Blowes, D.W. (2002). Multicomponent reactive transport modeling in variably saturated porous media using a generalized formulation for kinetically controlled reactions, Water Resources Research, 38, pp. 13-1-13-21, DOI: 10.1029/2001WR000862.

Morway, E.D., Niswonger, R.CH., Langevin, CH.D., Bailey, R.W. \& Healy, R.W. (2013). Modeling variably saturated multispecies reactive groundwater solute transport with MODFLOW-UZF and RT3D, Ground Water, 51, pp. 237-251, DOI: 10.1111/j.17456584.2012.00971.x.

Seidel-Morgenstern, A. (2004). Experimental determination of single solute and competitive adsorption isotherms. Journal of Chromatography A, 1037 (1-2), pp. 255-272, DOI: 10.1016/j. chroma.2003.11.108.

Szymański, K. \& Janowska, B. (2016). Migration of pollutants in porous soil environment, Archives of Environmental Protection, 42, (3), pp. 87-95, DOI: 10.1515/aep-2016-0026.

Szymkiewicz, R. (2010). Numerical modelling in open channel hydraulics, Water Science \& Technology Library, 83, Springer, Dordrecht, DOI: 10.1007/978- 90-481- 3674-2.

Taniguchi, M. \& Holman, I.M. (2010). Groundwater response to changing climate, CRC Press, DOI: 10.1201/b10530-18.

Yabusaki, S.B., Fang, Y., Williams, K.H., Murray, C.J., Ward, A.L., Dawault, R.D., Waichler, S.R., Necomer, D.R., Spane, F.A. \& Long, P.E. (2011). Variably saturated flow and multicomponent biogeochemical reactive transport modeling of uranium bioremedation field experiment, Journal of Contaminant Hydrology, 126, pp. 271-290, DOI: 10.1016/j. jconhyd.2011.09.002.

Zheng, CH. \& Wang, P.P. (1996). MT3DMS: A modular transport three-dimensional multispecies transport model for simulation of advection, dispersion, and chemical reactions of contaminants in groundwater systems; Documentation and user's guide, Dept. of Geol. Sci., University of Alabama, Tuscaloosa, AL 35487, Contract Reports SERDP-99-1.

\section{Zdolność adsorpcyjna wybranego piaszczystego gruntu względem zanieczyszczeń przemieszczających się $\mathbf{z}$ wodą gruntową}

Streszczenie: Jednym z najważniejszych problemów dotyczących przepływu zanieczyszczeń w wodzie gruntowej jest problem związany z określeniem parametrów charakteryzujących zdolność adsorpcyjną gruntu dla wybranych zanieczyszczeń przemieszczających się z wodą gruntową. W tym artykule, dla chlorowych i siarczanowych wskaźników przemieszczających się w piaszczystym gruncie, wzięto pod uwagę liczbowe wartości współczynników retardacji $\left(R_{q}\right)$ (traktowanych jako wartości średnie) oraz porowych prędkości wody gruntowej $\mathrm{z}$ adsorpcją $\left(u_{r} / R_{a}\right)$ (w przestrzeniach makro-porowych gruntu). W oparciu o $2 \mathrm{D}$ równanie transportu obliczono maksymalne bezwymiarowe wartości stężeń $\left(C_{\text {max }}^{*}\right)$ w wybranych przekrojach gruntowych. Wszystkie prezentowane obliczenia numeryczne odniesiono do niepublikowanej serii pomiarowej oznaczonej w pracy jako: Październik 1982. Dla tej serii pomiarowej obliczone numerycznie wartości stężeń porównano z pomierzonymi wartościami stężeń $\left(C_{\max m}^{*}\right)$, które udostępniono ostatnio autorowi pracy. W końcowej częśsi pracy parametry charakteryzujące zdolność adsorpcyjną $\left(R_{a}, u_{\gamma} / R_{a}\right)$ porównano również z takimi samymi parametrami obliczonymi dla dwóch wcześniejszych serii pomiarowych. Takie porównanie pozwoliło również oszacować stopniowe w czasie wyczerpywanie się zdolności adsorpcyjnej dla wybranego gruntu piaszczystego. 